\title{
PENERAPAN ALGORITMA ROUND ROBIN PADA PENJADWALAN PREVENTIVE MAINTENANCE DI PT. PASIFIK SATELIT NUSANTARA
}

\author{
Ahmad Zakir ${ }^{1)}$, Sheila Azhari Dalimunthe ${ }^{2)}$, Dedy Irwan ${ }^{3)}$ \\ 1,2,3 Fakultas Teknik Dan Komputer, Universitas Harapan Medan \\ email: suratzakir@gmail.com, sheilaazhari787@gmail.com,ddirwan@gmail.com
}

\begin{abstract}
Scheduling is needed when several activities must be processed at a certain time. Good scheduling maximizes the effectiveness of the use of every activity, so scheduling is an important part of planning and controlling activities. At PT. Pasifik Satelit Nusantara, there are maintenance activities on the devices used by the preventive maintenance process customers needed so that no additional costs occur, so it needs to be done scheduling that can minimize downtime. For this reason, the schedule must be in accordance with the actual conditions in the company so as to minimize downtime so that the process of customer activity is not hampered by damaged equipment. In this study utilizing a round robin algorithm that can schedule human resources that carry out preventife maintenance activities. The author uses website-based media so that it can easily be used by company superiors to schedule technicians or workers.
\end{abstract}

Keywords: Scheduling, Algorithm, Website

\section{PENDAHULUAN}

Penjadwalan diperlukan ketika beberapa kegiatan harus diproses pada suatu waktu tertentu. Penjadwalan yang baik memaksimumkan efektivitas pemanfaatan setiap kegiatan yang ada, sehingga penjadwalan merupakan bagian yang penting dalam perencanaan dan pengendalian kegiatan [1]. Mengidentifikasi beberapa tujuan dari aktivitas penjadwalan, yaitu yang pertama adalah meningkatkan utilisasi penggunaan sumber daya, atau dengan kata lain mengurangi waktu tunggu dari sumber daya tersebut, sehingga total waktu proses dapat berkurang dapat meningkat. Kedua, mengurangi rata-rata jumlah kegiatan yang menunggu dalam antrian proses ketika sumber daya yang ada masih mengerjakan tugas lain, dan yang ketiga, mengurangi keterlambatan, yaitu menjamin pemenuhan waktu yang tersedia [2].

Dalam sistem perangkat keras suatu perusahaan pada umumnya memiliki kegiatan pemeliharaan sebagai penunjang kegiatan operasional sistem. Pada dasarnya tindakan pemeliharaan ditujukan untuk menjaga availabilitas sistem, mempertahankan kelangsungan operasional dan kinerja sistem agar berjalan sesuai dengan yang diharapkan [3]. Perawatan merupakan suatu kegiatan yang dilakukan untuk memelihara atau menjaga suatu barang/peralatan yang dirawat agar tetap dapat berfungsi dengan baik. Perawatan terhadap produk produk perusahaan sangat penting untuk menjaga kelancaran proses kegiatan agar dapat berjalan dengan normal dan menghemat biaya, sehingga demand dapat terpenuhi tepat pada waktunya. Apabila perawatan dilakukan terlambat, maka akan menimbulkan kerugian bagi perusahaan [4], [5].

Masalah penjadwalan pemeliharaan ini merupakan salah satu aspek penting bagi kelancaran kegiatan operasional perusahaan. Demikian pula halnya pada PT. Pasifik Satelit Nusantara yang merupakan salah satu perusahaan yang bergerak di bidang telekomunikasi berbasis satelit yang menjual alat alat komunikasi berbasis satelit kepada para pelanggan yang membutuhkan Dalam sistem operasinya perusahaan memiliki banyak produk satelit yang di produksi untuk dijual atau disewakan kepada pelanggan.

Untuk menjaga produktivitas setiap perangkatnya yang digunakan oleh perusahaan maka perusahaan perlu melakukan pemeliharaan perangkat yang digunakan. Adapun salah satu pemeliharaan yang diterapkan di PT. Pasifik Satelit Nusantara adalah pemeliharaan pencegahan. Kegiatan ini merupakan tindakan penjadwalan kegiatan pemeriksaan untuk mengurangi kerusakan atau memperpanjang masa hidup dari komponen yang digunakan.

Setiap kegiatan pemeliharaan tersebut akan dilakukan bergantian terhadap perangkat 
yang digunakan oleh pelanggan yang ada. Untuk kegiatan pemeliharaan yang akan dilakukan memerlukan sejumlah sumber daya tenaga kerja ahli yang tidak berasal dari dalam perusahaan dan sejumlah tenaga kerja pembantu [3], [6]. Apabila, dalam kegiatannya terjadi keterlambatan dan kerusakan perangkat maka perusahaan akan menambah biaya sesuai dengan kontrak yang sudah disepakati sehingga menjaga perangkat dalam kondisi yang normal membutuhkan teknik perawatan untuk mencegah kerusakan. Maka untuk menjawab permasalahan yang dihadapi, agar tidak terjadi penambahan biaya kegiatan perawatan maka perlu dilakukan penjadwalan yang dapat meminimasi downtime. Untuk itu, jadwal yang dibuat harus sesuai dengan kondisi aktual yang ada diperusahaan agar dapat meminimasi downtime sehingga proses kegiatan pelanggan tidak terhambat oleh perangkat yang rusak. Adapun tujuan penelitian ini adalah menghasilkan sistem yang dapat mengelola jadwal preventive maintenance, memperbaiki sistem yang lama yang masih menggunakan sistem manual menjadi sistem yang terkomputerisasi dan memberikan solusi informasi penjadwalan preventive maintenance apabila terjadi humam error

\section{METODE PENELITIAN}

Adapun tahapan penelitian yang dilakukan dalam menyelesaikan perancangan ini adalah:

\section{1). Penelitian Pustaka (Library Research)}

Pada tahap ini, dilakukan pencarian informasi dan referensi melalui buku-buku, internet, atau bahan lainnya yang berkaitan dengan topik yang dibahas, seperti tentang penjadwalan maintenance

2). Pengumpulan Data

Pada tahap ini mengumpulkan bahan-bahan berupa hardware, software dan buku-buku yang berhubungan dengan perancangan yang dibuat.

3). Analisis perancangan sistem

Pada tahap ini menggunakan tahapan dari metedologi extream programming yang meliputi tahap perencanaan, kebutuhan sistem, desain sistem serta pengujian sistem dan merangkumnya sehingga dapat ditarik kesimpulan yang dijadikan tolak ukur pembuatan dan pengembangan sistem

4). Implementasi dan pengujian sistem

Pada tahap ini, dilakukan implementasi dan pengujian sistem berdasarkan rancangan yang dilakukan pada tahap sebelumnya.
Analisa Algoritma Round Robin

Round robin merupakan penjadwalan yang paling tua, sederhana, adil, banyak digunakan algoritmanya dan mudah diimplementasikan. Penjadwalan ini bukan dijalankan oleh proses lain tetapi oleh penjadwal berdasarkan lama waktu berjalannya proses (preempt by time). Penjadwalan tanpa prioritas berasumsi bahwa semua proses memiliki kepentingan yang sama, sehingga tidak ada prioritas tertentu. Semua proses dianggap penting sehingga diberi sejumlah waktu oleh pemroses yang disebut kwanta (quantum) atau time slice dimana proses itu berjalan. Jika proses masih running sampai akhir quantum, maka CPU akan mem-preempt proses itu dan memberikannya ke proses lain.

Berikut adalah contoh kasus penjadwalan proses dengan menggunakan Algoritma Round Robin dengan mencari waktu tunggu rata-rata setiap proses.

Sebuah CPU dengan quantum 4 mendapat beberapa proses dengan waktu kedatangan yang bersamaan seperti berikut:

Tabel 1. Waktu Kedatangan

\begin{tabular}{|l|l|}
\hline \multicolumn{1}{|c|}{ Proses } & \multicolumn{1}{|c|}{ Burst Time } \\
\hline P1 & 5 \\
\hline P2 & 10 \\
\hline P3 & 7 \\
\hline P4 & 6 \\
\hline P5 & 4 \\
\hline
\end{tabular}

Kemudian melakukan Gantt Chart Masukkan proses yang berurutan, kemudian kurangi Burst Time dengan nilai quantum.

P1:

Burst time - Quantum

$5-5=0$.

Waktu $=5$

P2:

Burst time - Quantum

$10-5=5$.

Sisa $=5$

Waktu $=5$

P3:

Burst time - Quantum

$7-5=2$.

Sisa $=2$

Waktu $=5$ 
P4:

Burst time - Quantum

$6-5=1$.

Sisa $=1$

Waktu antrian $=5$

P5:

Burst time - Quantum

$4-5=(-1)$.

Waktu antrian $=4$

Proses yang memiliki sisa, kemudian

dimasukkan kembali kedalam antrian sesuai dengan urutan Prosesnya.

P2:

Sisa Burst time - Quantum

$5-5=0$

Sisa $=0$

Waktu antrian $=5$

P3:

Sisa Burst time - Quantum

$2-5=(-3)$

Waktu antrian $=3$

P4:

Sisa Burst time - Quantum

$1-5=(-4)$

Waktu antrian $=1$

P2:

Sisa Burst time - Quantum

$1-5=(-4)$

Waktu antrian $=1$

Tabel 2. Hasil Perhitungan

\begin{tabular}{|l|l|l|l|l|l|l|l|l|}
\hline P1 & P2 & P3 & P4 & P5 & P2 & P3 & P4 & P2 \\
\hline 0 & 5 & 10 & 15 & 20 & 25 & 28 & 29 & 30 \\
\hline
\end{tabular}

Kemudian lakukan perhitungan Menghitung AWT (Average Waiting Time)

Tabel 3. Perhitungan Average Waiting Time

\begin{tabular}{|l|l|}
\hline Proses & \multicolumn{1}{|c|}{ Waiting Time } \\
\hline P1 & $\begin{array}{l}0 \text { (karena p1 proses yang pertama jadi } \\
\text { waiting time nya 0) }\end{array}$ \\
\hline P2 & $5+(25-10)+(30-28)=22$ \\
\hline P3 & $10+(28-15)=23$ \\
\hline P4 & $15+(29-20)=24$ \\
\hline P5 & 20 \\
\hline
\end{tabular}

AWT yang terjadi adalah:

$(0+22+23+24+20) / 5$

$=89 / 5$

$=17,8$

Menghitung ATAT (Average Turn Arround Time)
Tabel 2. Average Turn Arround Time

\begin{tabular}{|l|l|l|l|l|l|l|}
\hline $\begin{array}{l}\text { Pros } \\
\text { es }\end{array}$ & $\begin{array}{l}\text { Saa } \\
\text { t } \\
\text { Tib } \\
\text { a }\end{array}$ & $\begin{array}{l}\text { Lam } \\
\text { a } \\
\text { Pros } \\
\text { es }\end{array}$ & $\begin{array}{l}\text { Saat } \\
\text { mul } \\
\text { ai }\end{array}$ & $\begin{array}{l}\text { Saat } \\
\text { seles } \\
\text { ai }\end{array}$ & $\begin{array}{l}\text { Waiti } \\
\text { ng } \\
\text { tima }\end{array}$ & $\begin{array}{l}\text { Turn } \\
\text { arou } \\
\text { nd } \\
\text { time }\end{array}$ \\
\hline P1 & 0 & 5 & 0 & 5 & 0 & 5 \\
\hline P2 & 0 & 10 & 5 & & 22 & 30 \\
\hline P3 & 0 & 7 & 10 & & 23 & 28 \\
\hline P4 & 0 & 6 & 15 & & 24 & 29 \\
\hline P5 & 0 & 4 & 20 & & 20 & 25 \\
\hline \multicolumn{7}{|c|}{ Rata rata } \\
\hline
\end{tabular}

\section{Usecase Diagram}

Use case diagram menggambarkan fungsionalitas yang di harapkan dari sebuah pembuatan sistem sistem informasi jadwal Teknisi yang mendeskripsikan sebuah interaksi antara satu atau lebih aktor dengan proses yang akan di buat, berikut ini perancangan use case sistem yaitu:

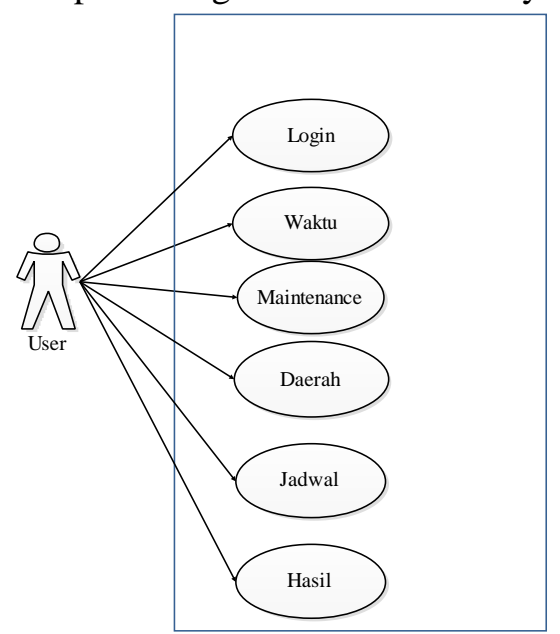

Gambar 1. Use Case Diagram sistem

Dalam Use Case Diagram di atas dijelaskan bahwa dalam user terdapat menu menu yang berfungsi memudahkan user dalam menggunakan sistem informasi penjadwalan yang terdiri dari menu menu seperti, login, waktu, maintenance, daerah jadwal. Dalam menu ini terdaapat banyak informasi sehingga pengguna dapat mengetahui informasi tentang jadwal preventive maintenance.

\section{Sequence Diagram Login Admin}

Sequence diagram login menggambarkan alur kerja dari system ketika melakukan login yang dilakukan oleh admin atau pengguna, untuk dapat masuk kehalaman administrator menu admin yang berfungsi melakukan pengolahan data seperti menambah, mengedit, dan menghapus. Berikut adalah sequence diagram login admin yang dirancang penulis pada Gambar 2. 


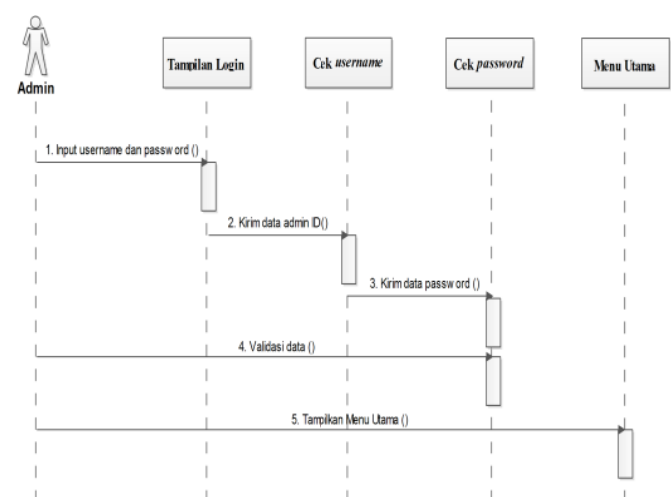

Gambar 2. Sequence diagram login admin

Sequence Diagram Menu Utama User

Sequence diagram user menggambarkan alur kerja dari system kepada user ketika menggunakan sistem penjadwalan Teknisi. Sequence diagram login admin yang dirancang dapat dilihat pada gambar 3 .

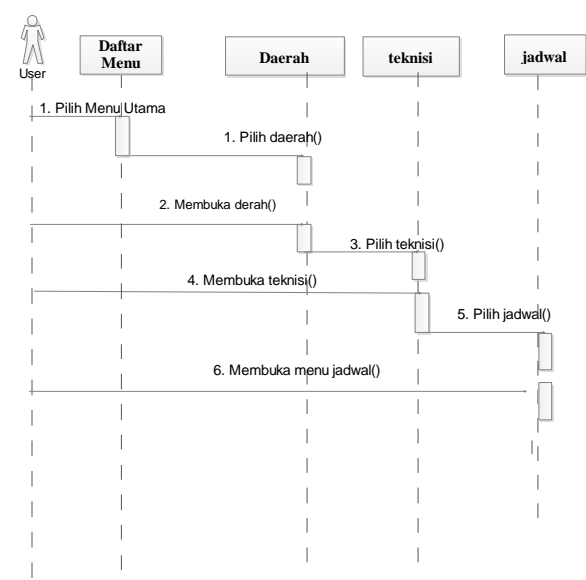

Gambar 3. Sequence diagram user

\section{Activity Diagram Menu Teknisi}

Berikut desain activity diagram menu teknisi yang penulis rancang dapat dilihat pada Gambar 4.

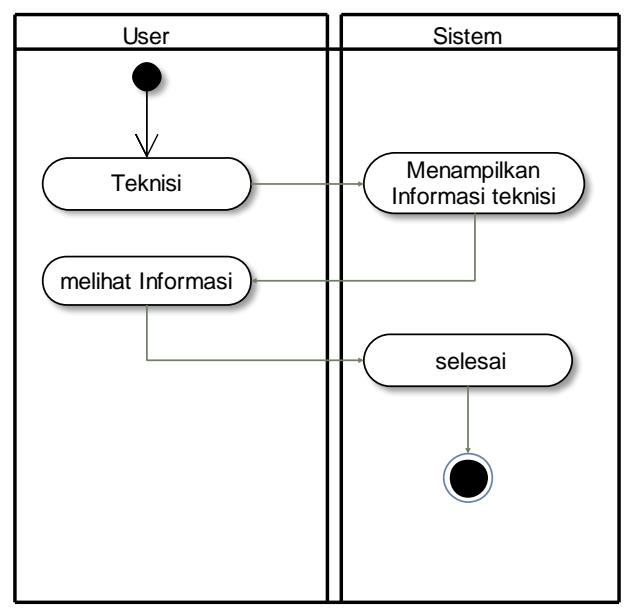

Gambar 4. Activity Diagram menu teknisi

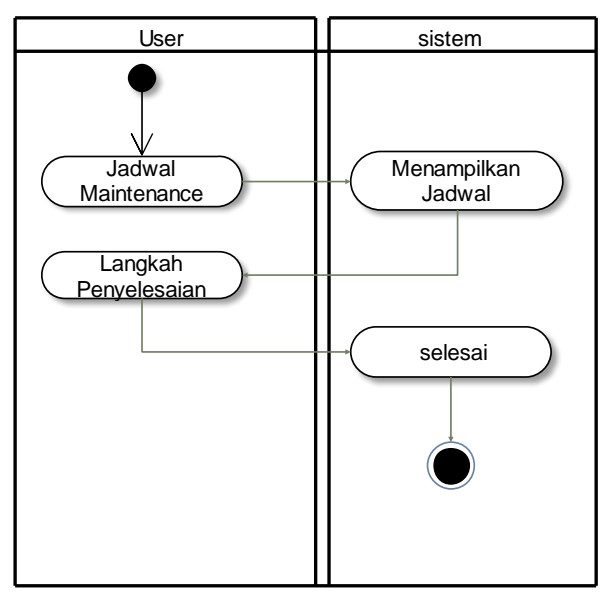

Gambar 5. Activity Diagram menu jadwal

\section{Flowchart}

Berikut ini flowchart sistem dari sistem penjadwalan preventife maintenance:

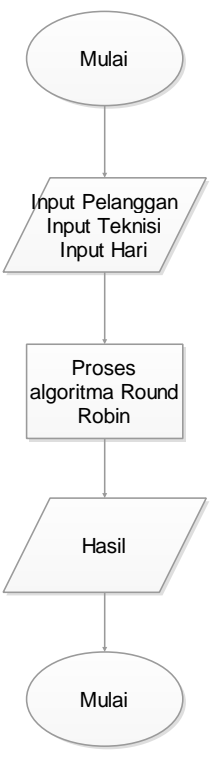

Gambar 6. Class Diagram

Gambar 6 menjelaskan bahwa flowchart akan menggambarkan proses alur kerja sistem, awal mula sistem akan melakukan input data pelanggan, input data teknisi, input data waktu kemudian algoritma round robin akan melakukan proses penjadwalan

\section{HASIL DAN PEMBAHASAN}

Implementasi dilakukan setelah perancangan selesai dilakukan dan selanjutnya akan diimplementasikan pada bahasa pemrograman yang akan digunakan. Tujuan implementasi adalah untuk mengkonfirmasikan modul program perancangan kepada pengguna sistem sehingga user dapat memberi masukan kepada pembangun sistem. Pada Sistem 
penjadwalan preventife maintenance pada PT. Pasifik Satelit Nusantara menggunakan algoritma roud robin akan dilakukan implementasi sistem dan akan ditampilkan sehingga pengguna dapat memberikan masukan, sistem ini dibangun menggunakan Bahasa pemrograman PHP dan Mysql sebagai database nya

\section{Tampilan Menu Login}

Pada menu login user pada Sistem terdapat form username dan password, username ialah id pengguna yang sudah terdaftar didalam database. Dalam sistem ini, sebelum dapat melaksanakan tugas administratifnya, maka user admin pusat harus melakukan proses login terlebih dahulu sesuai dengan data yang sudah dientrykan di pemeliharaan data admin pusat. Tampilan untuk login dapat dilihat pada gambar 7.

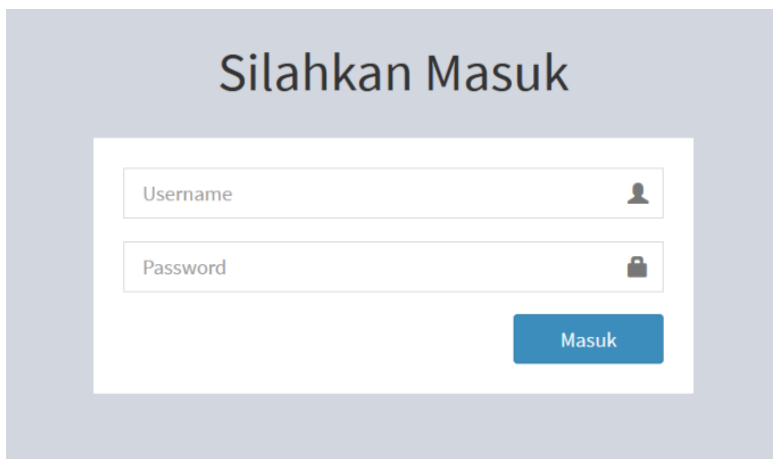

Gambar 7. Tampilan Menu login sistem

Berdasarkan gambar 7 dijelaskan bahwa dalam Tampilan login user hal yang pertama yang harus dilakukan oleh user adalah masuk kehalaman login /halaman tampilan utama sistem. Kemudian melakukan pengisian username dan password pada form login. Jika username dan pasword yang di masukan salah, Maka sistem akan menampilkan form login kembali dan melakukan pengisian username dan password lagi. Dan jika benar maka sistem akan menampilkan halaman menu utama dan selanjutnya pengguna dapat mengakses menu-menu yang disediakan sesuai dengan kebutuhan.

\section{Tampilan Menu Utama}

Tampilan menu utama akan menampilkan semua menu yang ada pada Sistem penjadwalan preventife maintenance pada PT. Pasifik Satelit Nusantara menggunakan algoritma Roud Robin. Pada sistem ini akan menampilkan menu menu seperti beranda, data waktu, data maintenance, data produk dan data penjadwalan. Berikut ini adalah tampilan menu utama yang sudah siap diimplementasikan dapat dilihat pada Gambar 8.

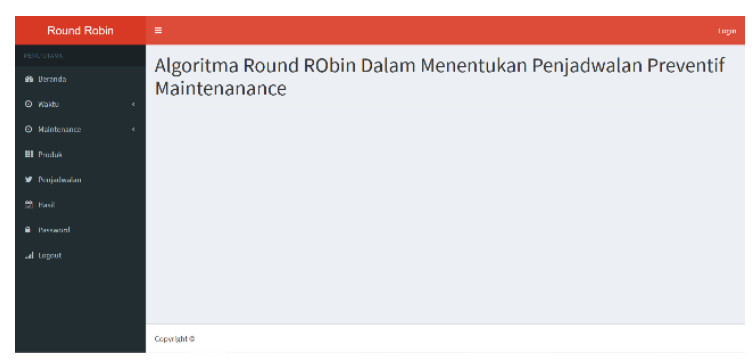

Gambar 8. Tampilan Menu Utama

Keterangan gambar 8 .

1. Beranda merupakan tampilan utama pada Sistem

2. Menu waktu akan menampilkan keseluruhan data waktu seperti data hari, data jam yang dapat dirubah sesuai kebutuhan

3. Menu data maintenance merupakan menu yang berfungsi sebagai menu yang dapat menampilkan data teknisi dan pelanggan

4. Menu produk merupakan tampilan informasi dari produk yang digunakan oleh pelanggan

5. Menu penjadwalan merupakan proses dari algoritma round robin

3. Tampilan Menu waktu

Tampilan menu waktu akan menampilkan keseluruhan dari data waktu yang terdapat pada Sistem penjadwalan preventife maintenance pada PT. Pasifik Satelit Nusantara menggunakan algoritma roud robin, berikut ini adalah tampilan menu waktu yang sudah siap diimplementasikan, dapat lihat pada Gambar 9.

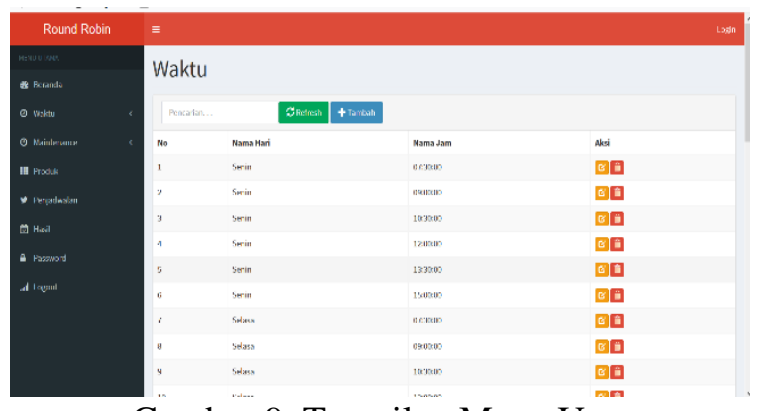

Gambar 9. Tampilan Menu User

Keterangan gambar 9 pada tampilan data waktu sebagai berikut

1. Pada menu data waktu terdapat tabel yang akan menampilkan informasi dari data waktu seperti nama hari, jam dan aksi 
2. Pada button aksi administrator dapat melakukan perubahan data, penambhan data serta menghapus data sesuai dengan kebutuhan

\section{Tampilan Menu tambah data waktu}

Tampilan menu tambah data waktu akan menampilkan keseluruhan form dari data waktu yang terdapat pada sistem Sistem penjadwalan preventife maintenance pada PT. Pasifik Satelit Nusantara menggunakan algoritma roud robin, berikut ini adalah tampilan menu tambah data waktu yang sudah siap diimplementasikan, lihat pada Gambar 10.

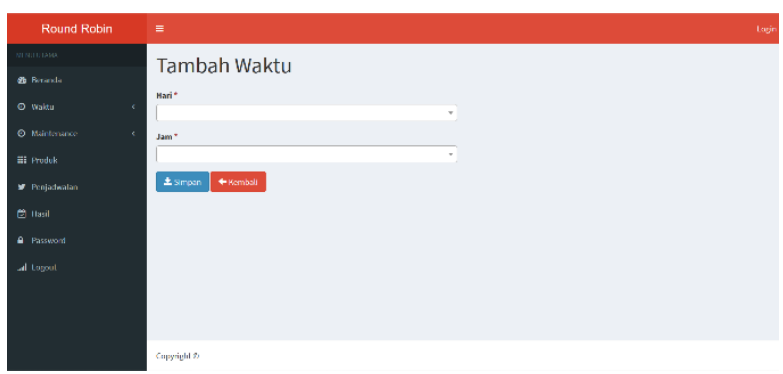

Gambar 10. Tampilan Menu tambah data waktu

Keterangan gambar 10. pada tampilan tambah data waktu sebagai berikut

1. Pada menu tambah data waktu terdapat form yang akan digunakan untuk melakukan penambahan waktu sepertihari dan jam

2. Pada button simpan dapat melakukan perubahan data, penambhan data serta menghapus data sesuai dengan kebutuhan.

\section{Tampilan Menu Data Maintenance}

Tampilan menu data maintenance merupakan menu yang akan menampilkan data maintenance yang sudah diinputkan oleh administrator pada sistem sudah dibangun dapat dilihat pada Gambar 11.

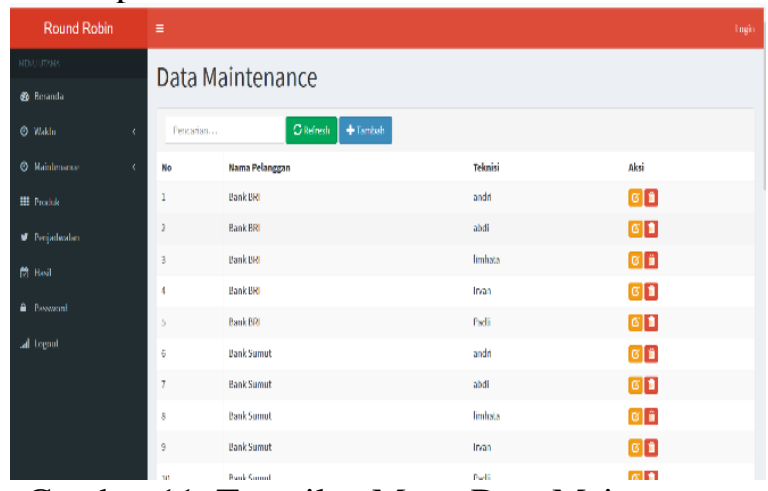

Gambar 11. Tampilan Menu Data Maintenance
Keterangan gambar 11 pada tampilan maintenance sebagai berikut

1. Pada menu data maintenance terdapat tabel yang akan menampilkan informasi dari data maintenance seperti data pelanggan dan teknisi

2. Pada button aksi administrator dapat melakukan perubahan data, penambhan data serta menghapus data sesuai dengan kebutuhan

\section{Tampilan Tambah Data Maintenance}

Tampilan tambah data maintenance merupakan tampilan yang dapat dilihat oleh user untuk melakukan penambahan data maintenance, berikut ini tampilan data maintenance yang sudah dibangun dapat dilihat pada Gambar 12.

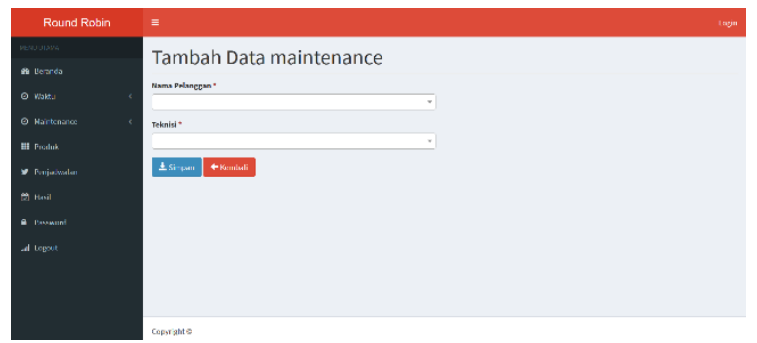

Gambar 12 Tampilan menu tambah data maintenance

Keterangan gambar 12 pada tampilan tambah data maintenance sebagai berikut

1. Pada menu tambah data maintenance terdapat form yang akan digunakan untuk melakukan penambahan data maintenance seperti data pelanggan dan teknisi

2. Pada button simpan a dapat melakukan perubahan data, penambahan data serta menghapus data sesuai dengan kebutuhan

\section{Tampilan Menu Data produk}

Tampilan menu data produk merupakan menu yang akan menampilkan data keseluruhan produk yang sudah diinputkan oleh administrator pada sistem sudah dibangun dapat dilihat pada Gambar 13.

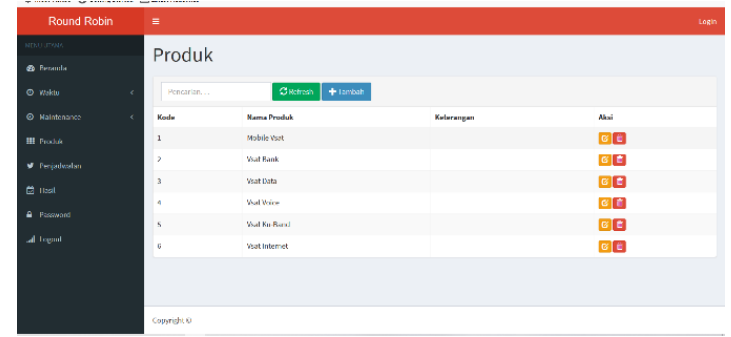

Gambar 13. Tampilan Menu Data Produk 
Keterangan gambar 13 pada tampilan data produk sebagai berikut

1. Pada menu data produk terdapat tabel yang akan menampilkan informasi dari data produk seperti nama produk dan keterangan

2. Pada button aksi administrator dapat melakukan perubahan data, penambhan data serta menghapus data sesuai dengan kebutuhan

\section{Tampilan Tambah Data produk}

Tampilan tambah data produk merupakan tampilan yang dapat dilihat oleh user untuk melakukan penambahan data produk, berikut ini tampilan data produk yang sudah dibangun dapat dilihat pada Gambar 14.

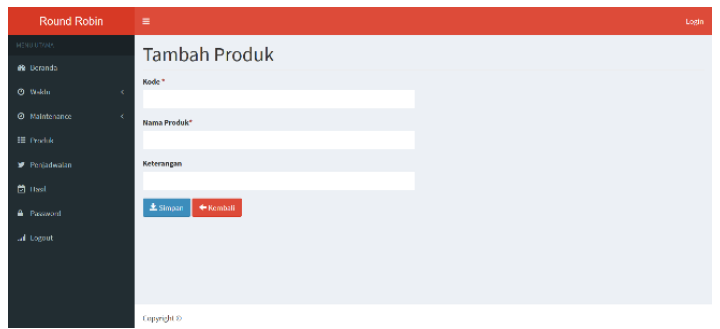

Gambar 14. Tampilan menu tambah data produk

Keterangan gambar 14 pada tampilan tambah data produk sebagai berikut:

1. Pada menu data produk terdapat form yang akan digunakan untuk melakukan penambahan data produk seperti nama produk dan keterangan

2. Pada button simpan dapat melakukan perubahan data, penambhan data

9. Tampilan Menu produk generate jadwal

Tampilan menu generate jadwal merupakan tampilan yang akan muncul Ketika pengguna atau user melakukan generate jadwal pada menu penjadwalan pada sistem untuk mendapatkan hasil penjdwalan preventife maintenance, berikut ini tampilan menu proses generte jadwal pengguna yang sudah dibangun dapat dilihat pada Gambar 15.

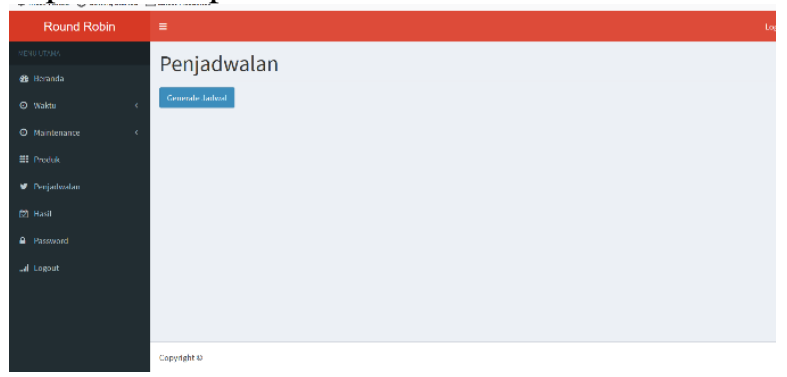

Gambar 15. Menu proses generate penjadwalan
Keterangan gambar 15 pada tampilan proses generate jadwal akan melakukan proses penjadwalan dari algoritma round robin sehingga hasil yang didapatkan berupa penjadwalan preventife maintenance

\section{Tampilan Menu hasil penjadwalan}

Tampilan menu hasil penjadwalan merupakan tampilan yang akan muncul Ketika pengguna mendapatkan hasil dari algoritma round robin dalam melakukan penjadwalan, berikut ini tampilan menu hasil yang sudah diimplementasikan pada Gambar 16.

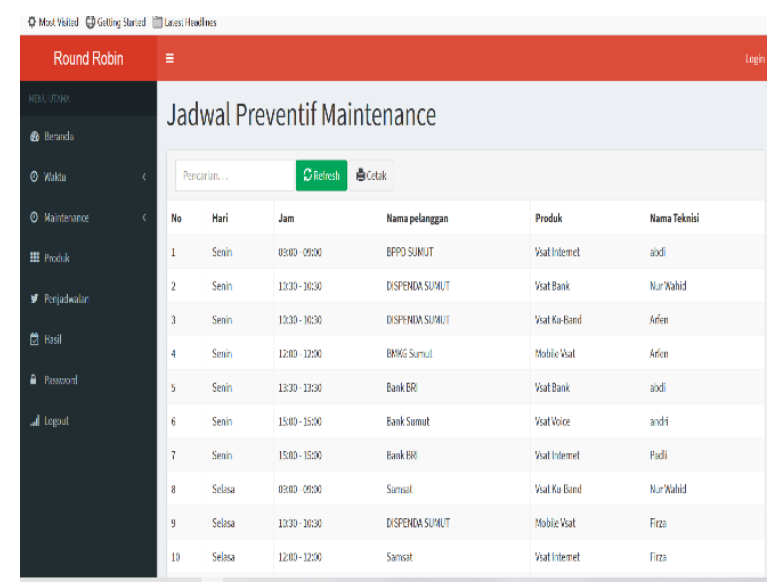

Gambar 16 Tampilan Menu Hasil Penjadwalan

Keterangan gambar 16 pada tampilan hasil jadwal sebagai berikut

1. Pada menu data hasil jadwal akan menampilkan informasi dari penjadwalan yang sudah dilakukan dengan proses algoritma round robin

2. Pada hasil penjadwalan terdapat hari, jam, nama pelanggan, produk serta nama teknisi

\section{KESIMPULAN}

Dalam uraian rangkaian mulai dari proses pembuatan Sistem penjadwalan preventif maintenance pada PT. Pasifik Satelit Nusantara dengan menggunakan algoritma round robin, dapat ditarik beberapa kesimpulan penting antara lain:

1. Penelitian ini berhasil menghasilkan sebuah aplikasi optimasi penjadwalan preventive maintenance, aplikasi ini telah berhasil dijalankan dan memberikan output berupa hasil penjadwalan preventive maintenance

2. Memperbaiki sistem yang lama yang masih menggunakan sistem manual menjadi sistem yang terkomputerisasi dengan menerapkan 
algoritma round robin dalam membuat penjadwalan

3. Dengan Adanya aplikasi ini maka pengguna dapat mengetahui jadwal preventive maintenance sehingga memudahkan divisi operation maintenance menjalankan tugasnya masing masing

4. Memberikan solusi informasi penjadwalan preventive maintenance apabila terjadi human error

\section{REFERENSI}

[1] M. Destiningrum and Q. J. Adrian, "Sistem Informasi Penjadwalan Dokter Berbassis Web Dengan Menggunakan Framework Codeigniter (Studi Kasus: Rumah Sakit Yukum Medical Centre)," J. Teknoinfo, vol. 11, no. 2, p. 30, 2017.

[2] A. Wijaya and Gunawan, "Implementasi Algoritma Round Robin Pada Sistem Penjadwalan Mata Kuliah ( Studi Kasus : Universitas Muhammadiyah Bengkulu )," J. Inform. Upgris, vol. 4, no. 1, pp. 64-71, 2018.

[3] Y. Praharsi, I. K. Sriwana, and D. M. Sari, "Perancangan Penjadwalan Preventive Maintenance Pada Pt . Artha Prima Sukses Makmur," J. Ilm. Tek. Ind., vol. 14, no. 1, pp. 59-65, 2015.

[4] S. D. Pandi, H. Santosa, and J. Mulyono, "Perancangan Preventive Maintenance Pada Mesin Corruganting dan Mesin Flexo di PT. Surindo Teguh Gemilang," J. Ilm. WidyaTeknik, vol. 13, no. 1, pp. 33-38, 2014.

[5] T. Ramadhan and V. Utomo, "Rancang Bangun Aplikasi Mobile Untuk Notifikasi Jadwal," J. Teknol. Inf. dan Komunikasi, vol. 5, no. 1, pp. 47-55, 2014.

[6] A. Mugiarsih, "Sistem Informasi Jadwal Praktek Dokter Pada Klinik Bakti Ananda Berbasis Android," vol. 02, no. 01, pp. 6873, 2019. 